SCIENTIFIC REPORT

\title{
Exfoliation syndrome angle characteristics: a lack of correlation with amount of disc damage
}

\author{
C J Cobb, G Blanco, G L Spaeth
}

Br J Ophthalmol 2004;88:1002-1003. doi: 10.1136/bjo.2003.031732

Background/aims: The exact pathogenesis of glaucoma in exfoliation syndrome is unclear. There has been some suggestion that narrow angles are more common in exfoliation syndrome and that this may be a component in the disease. The degree of pigmentation has also been shown to influence the intraocular pressure. The aim was to determine whether gonioscopic features of the anterior chamber angle in patients with exfoliation syndrome correlate with severity of the glaucoma.

Methods: A prospective study of consecutive patients with exfoliation syndrome was carried out. 78 patients with exfoliation syndrome were examined by one clinician (GLS), and underwent gonioscopy and dilated funduscopy.

Results: Anterior chamber angle, level of iris insertion, degree of pigmentation and the presence or absence of a Sampaolesi line were not correlated with the degree of disc damage.

Conclusions: There was no apparent association between angle characteristics and the severity of glaucoma in patients with exfoliation syndrome.

$\mathrm{E}$ xfoliation syndrome (ES) is currently one of the most common clinically identifiable pathological entities to cause glaucoma. It is characterised by the presence of fibrillogranular material throughout the anterior segment (see table 1). The diagnosis of exfoliation is made by visualising the exfoliative material on the pupillary ruff and/or on the anterior lens capsule. Exfoliative material (PXM) has been found in the conjunctiva of fellow eyes in unilateral ES. ${ }^{1}$ It has been postulated that the conjunctival changes may precede the development of PXM on the lens surface, this idea has led Prince $e t a l^{2}$ to define a category of patients that they refer to as ES suspects. The features of the ES suspects are shown in table 1 under features suggestive of ES.

The exact pathogenesis of the glaucoma is unknown. As the glaucoma is usually more severe in the eye with the most pronounced exfoliative features, including pigmentation of the angle, ${ }^{34}$ it is postulated that the mechanism involves accumulation of the exfoliative material and pigment granules in the trabecular meshwork, which in turn causes damage. The glaucoma associated with exfoliation syndrome is usually associated with a normal configuration of the drainage angle although Layden and Shaffer and Wishart et al reported $23 \%{ }^{5}$ and $32 \%^{6}$ of narrow angles in their series of gonioscopic evaluation of ES patients compared to the 5\% seen in the normal population. ${ }^{7}$ This then calls into question the role of the angle configuration in the development of glaucoma. Is the narrowing of the angle responsible for the development of glaucoma?

It is also well known that glaucoma in the exfoliation syndrome usually has a more serious clinical course than primary open angle glaucoma and can respond differently to different treatments. ${ }^{8}$ It is therefore important, firstly, to identify patients with ES or who may have ES and, secondly, to determine which of those patients will develop glaucoma and therefore need closer follow up.

Many authors have correlated optic disc morphology with visual field defects and nerve fibre layer thickness. ${ }^{9}{ }^{10}$ In fact, disc changes can precede detectable visual field loss. Automated visual field testing can be highly subjective and is not always possible in some patients. Bayer et al describe a new disc grading system which correlates well with visual field damage. ${ }^{11}$ By using this new method of disc grading as a way of estimating glaucomatous loss, the subjectivity of visual field testing has been replaced by the subjectivity of one observer. This study was undertaken to establish whether features of the anterior chamber angle anatomy were associated with glaucomatous damage using this disc grading system.

\section{METHODS}

One of the authors (GLS) examined prospectively 78 consecutive patients with ES (defined by the presence of fibrillary material on the pupillary ruff or the anterior lens capsule following dilatation) or a suspicion of ES (the presence of a Sampaolesi line on gonioscopy) attending a hospital based private glaucoma practice. All patients had gonioscopy preformed and dilated funduscopy by the one physician. Those excluded were any patient who had had previous intraocular surgery, a history of severe ocular injury, and a history of severe anterior uveitis.

If the patient had bilateral ES the eye with the most pigmentation was assigned as the worse eye and included for analysis. The following characteristics were recorded from the case notes: (1) date of examination, (2) age, (3) sex, (4) race, (5) number of affected eyes, (6) IOP in each eye, (7) angle insertion, Spaeth classification, ${ }^{7}(8)$ depth of anterior chamber angle in degrees, (9) iris plane configuration, Spaeth classification, ${ }^{7}(10)$ inferior pigmentary trabecular meshwork pigmentation grade 0 to 4 , (11) superior pigmentary trabecular meshwork pigmentation grade 0 to 4 , (12) presence or absence of a Sampaolesi line, (13) glaucoma disc stage, disc damage likelihood scale (DDLS). ${ }^{11}$

\section{RESULTS}

The average age of those patients with ES was 68 (SD 12) years (range 45-90 years) and of those who were ES suspects it was 69 (8) years (47-91 years). There was no significant age difference between the two groups $(p=0.67$, independent samples $t$ test). The average maximum IOP in those with ES was 24.4 (9.3) $\mathrm{mm} \mathrm{Hg}$ (11-58 $\mathrm{mm} \mathrm{Hg}$ ) compared to 22.5 (4.7) $\mathrm{mm} \mathrm{Hg}(15-34 \mathrm{~mm} \mathrm{Hg})$ in the ES suspects. Again, this

Abbreviations: ES, exfoliation syndrome; PXM, pseudoexfoliative material 


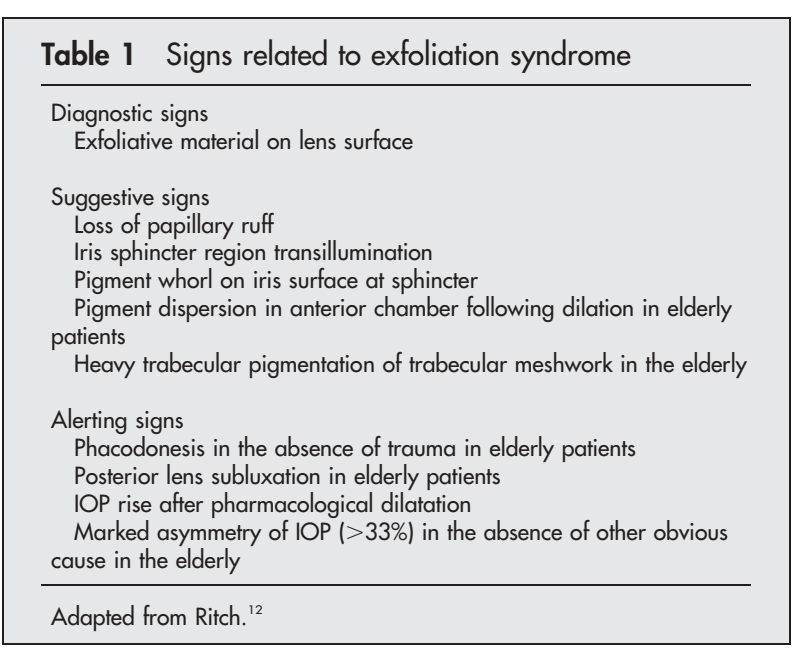

difference was not significant $(\mathrm{p}=0.23$ independent samples $t$ test).

Using the Pearson correlation coefficient, the actual anterior chamber angle in degrees and the maximum recorded intraocular pressure showed no significant correlation with the DDLS. There was a weakly significant correlation with age $(\mathrm{R}=0.285, \mathrm{p}=0.011$ Pearson correlation). The Spearman correlation coefficient showed there was no significant correlation between DDLS and the degree of pigmentation in the angle. Also, there was no significant correlation between the DDLS score and the site of the insertion of the iris using one way ANOVA $(p=0.28)$.

Using multilinear regression analysis, for the entire cohort, only $17 \%$ of the variability could be explained by age, sex, maximum IOP, and the angle characteristics (iris insertion, pigmentation, and angle in degrees). Only age was significant $(\mathrm{p}=0.008)$. When looking at the two groups separately (ES and ES suspects) $\mathrm{R}^{2}$ was $21 \%$ and $30 \%$, respectively. Age was a more helpful predictor of DDLS stage in the suspect group than it was among those with definite ES.

\section{DISCUSSION}

The DDLS, an indicator of the severity of glaucoma, was not significantly associated with angle characteristics such as the degree of pigmentation, the level of iris insertion, or the angle between the iris and the trabecular meshwork. This would suggest that the standard angle characteristics have no bearing on the severity of glaucoma. A number of studies have shown a higher prevalence of narrow and occludable angles in $\mathrm{ES}^{56}$ and have postulated that this may be the mechanism for the rise in pressure and glaucomatous damage seen in some. The fact that the angle configuration is independent of the degree of damage suggests that this hypothesis is not correct, and that the mechanism of damage in ES is similar to that seen in open angle glaucoma.

The finding that the degree of pigmentation was not correlated with the degree of damage may be because of the small sample size. However, the average score for pigmentation in the ES and ES suspects combined was 2.65, compared to 1.82 in the fellow eyes with no ES or Sampaolesi line $(p=<0.0001)$. This suggests that degree of pigmentation is correlated with presence of disease but once ES is present the actual amount of pigmentation is high in all cases.

\section{ACKNOWLEDGEMENT}

We wish to thank Joann Fontanarosa, PhD, for her assistance with the statistical analysis.

\section{Authors' affiliations}

C J Cobb, Deprtment of Ophthalmology, Ninewells Hospital and Medical School, Dundee DDI 9SY, UK

G C Blanco, Clinica Alemana, Depto Santiago, Las Hualtatas, Chile G L Spaeth, William A and Anna V Goldberg Glaucoma Service and Research Laboratories of the Wills Eye Hospital, 900 Walnut Street, Philadelphia, PA, USA

Correspondence to: Dr Caroline Cobb, Department of Ophthalmology, Ninewells Hospital and Medical School, Dundee DDI 9SY, UK; caroline. cobb@tuht.scot.nhs.uk

Accepted for publication 15 December 2003

\section{REFERENCES}

1 Speakman JS, Ghosh M. The conjunctiva in senile lens exfoliation. Arch Ophthalmol 1976;94:1757-61.

2 Prince AW, Streeten BW, Ritch R, et al. Preclinical diagnosis of pseudoexfoliation syndrome. Arch Ophthalmol 1987; 105:1076-82.

3 Aasved H. Intarocular pressure in eyes with and without fibrillopthia epitheliocapsularis (so called senile exfoliation or pseudoexfoliation). Acta Ophthalmol 1971;49:601-10.

4 Moreno-Montanes J, Quinteiro Alonso A, Alvarez Serna A, et al. Exfoliation syndrome: clinical study of the irido-corneal angle. J Fr Ophtalmol 1990;13:183-8.

5 Layden WE, Shaffer RN. Exfoliation syndrome. Am J Ophthalmol 1974;78:835-841.

6 Wishart PK, Spaeth GL, Poryzees EM. Anterior chamber angle in exfoliation syndrome. Br J Ophthalmol 1985;69:103-7.

7 Spaeth GL. The normal development of the human anterior chamber angle: a new descriptive grading. Trans Ophthalmol Soc UK 1971;91:709-59.

8 Futa R Shimizu T, Furuyoshi N, et al. Clinical features of capsular glaucoma in comparison with primary open angle glaucoma in Japan. Acta Ophthalmol 1992:70:214-19.

9 Jonas JB, Grundler AE. Correlation between mean visual field loss and morphometric optic disc variables in the open angle glaucomas. Am J Ophthalmol 1997; 124:488-97.

10 Caprioli J. Correlation of visual function with optic nerve and nerve fibre layer structure in glaucoma. Surv Ophthalmol 1989;33:319-29.

11 Bayer A, Harasymowycz P, Henderer JD, et al. Validity of a new disk grading scale for estimating glaucomatous damage: correlation with visual field damage. Am J Ophthalmol 2002;133:758-63.

12 Ritch R. Exfoliation syndrome and occludable angles. Trans Am Ophthalmol Soc 1994;92:846-942. 